\title{
Erratum: European origin of placodont marine reptiles and the evolution of crushing dentition in Placodontia
}

\author{
James M. Neenan, Nicole Klein \& Torsten M. Scheyer
}

Nature Communications 4:1621 doi: 10.1038/ncomms2633 (2013); Published 27 Mar 2013; Updated 1 Oct 2013

The file containing Supplementary Data 1 was inadvertently omitted during production of this article and should have been referred to in the 'Phylogenetic analysis' section of the Methods, as follows: 'The character matrix used herein (Supplementary Data 1) is based on the matrix of Liu et al. ${ }^{11}$. Supplementary Data 1 is now available to download from the HTML version of this Erratum. 